\title{
Learning through reflection: Supervising DRC master's degree students within the open distance and learning context
}

\author{
Lizeth Roets \\ Department of Health Studies, University of South Africa, Pretoria, South Africa \\ Correspondence: Lizeth Roets. Address: Department of Health Studies, School of Social Sciences, Theo van Wyk \\ building, 7-183, Muckleneuk Campus Unisa, Pretoria, South Africa 0003. Telephone: 27-124-292-2226. Fax: 27- \\ 124-296-688. Email: roetsl@unisa.ac.za.
}

Received: August 9, 2012

DOI : 10.5430/jnep.v3n10p139
Accepted: October 8, $2012 \quad$ Online Published: July 10, 2013

URL: http://dx.doi.org/10.5430/jnep.v3n10p139

\begin{abstract}
The internationalisation of higher education is a global imperative that impacts on students and supervision practices in various ways. Culture and language diversity, as well as the characteristics of the students themselves in Open and Distance Learning, have been given little attention and the impact is not always taken into account. When implementing a scholarship development programme across language borders, factors such as culture and socio-economic background need to be taken into account because both can have an effect on the supervisory practices and success of such a programme. Supervision in a language not understood by the supervisor and the master's degree students in the DRC challenged traditional western methodologies and paradigms. A qualitative narrative reflection was therefore undertaken to both critically reflect on the challenges encountered and initiate innovative ideas. Indeed, I can say that, in my supervisory practice, the western body of knowledge was challenged. As a result, new research methodology initiatives to improve distance education research supervision had to be initiated and implemented.
\end{abstract}

\section{Key words}

Open and Distance Learning, Scholarship development, Supervision, Language diversity

\section{Introduction}

This article is my personal narrative of my experiences as a South African supervisor involved in Open and Distance Learning (ODL) in the Democratic Republic of the Congo (DRC). Narratives and storytelling are legitimate methodologies ${ }^{[1,2]}$ in qualitative research and are appropriate for the expression of my personal journey of experience. Reflection was the key in my self-regulatory learning as an educator and supervisor and is essential in my lifelong learning ${ }^{[3]}$. I realised, when supervising French students, that there is a need for supervisors in Open and Distance Learning to rethink their supervisory practices and roles. To me, reflexivity is a pre-requisite for innovative supervision practices in ODL.

I have personally experienced what Grant and Manathunga ${ }^{[4]}$ said about supervision: "our raced, classed and gendered bodies are present." Culture, in varied guises, impacts on supervision and mentoring. When we mentor or supervise across ethnic cultures ${ }^{[4]}$ in different contexts and in different languages over distance, our mentoring or supervision becomes a 
pedagogical site of rich possibility. At times, however, it can also be very puzzling and complex. This is because supervision is expected to "go smoothly", and because the domination of the western knowledge system is rarely challenged ${ }^{[4]}$. In the context of Africa, I have not experienced mentoring and supervision to be an easy process - for various reasons, of which one is the language barrier. A lack of resources and cultural differences were other factors that impacted on my supervisory practices.

The impact that culture, context and language diversity has on the outcomes of internationalisation is rarely discussed. Institutions in Africa take part in internationalisation mostly to strengthen research and to produce knowledge ${ }^{[5]}$ and therefore the impact of language; context and culture on both the supervisor and student became even more relevant. My experience in the DRC taught me that the challenges regarding supervision and mentoring of postgraduate students in ODL need to be taken seriously and reflected upon, in order to accomplish research-related outcomes.

In order to understand my reflective journey, the background and context of this study need to be described in some detail. The background to this study, then, was the acute shortage of doctors, nurses and midwives in sub-Saharan Africa ${ }^{[6]}$, a situation that demanded urgent attention. Educational responses to handle the shortage in the past had been ad hoc and outside the formal qualification framework and context of African countries, resulting in limited scope and depth of education (Memorandum of Understanding 2006:8), including nursing education.

The lack of postgraduate nursing programmes in the DRC ${ }^{[7]}$ is one of the reasons why nursing professionals are inadequately prepared for their task. This situation is exacerbated by the fact that their numbers are also insufficient to deal with Africa's health needs. The CHENMA project (Collaboration for Higher Education for Nurses and Midwives in Africa) made an attempt to address this need and initiated the first master's degree programme for nurses ${ }^{[8]}$ in the Democratic Republic of the Congo (DRC).

The DRC is a Franco-fan country, with a population of over 68 million people. Although a variety of languages are spoken, it is bridged by the use of French in Lubumbashi, where this research was done ${ }^{[9]}$. I was requested to act as the coordinator of the master's degree programme in Midwifery and Education, between the host South African university and a Higher Institute in the DRC. The only prerequisite for students to enroll in this programme was that students had to possess a basic degree in nursing. Access, further was open, not even English literacy was a pre-requisite for enrolment.

The challenges I experienced as a nurse educator and research supervisor forced me to think innovatively and use problemsolving techniques that contributed to my own scholarship development and the development of my students. Reflecting on my experiences highlighted the supervisory challenges I faced and gave me insight into my own behaviour and that of my students.

The purpose of this article is to describe my experiences as a mentor and research supervisor in the ODL context. I also want to share how reflexivity helped me to implement innovative ideas in my supervisory practice in the absence of a language mutually understood by the students and I.

\section{Problem statement}

Perhaps I should start by admitting that I was naive not to foresee the challenges I would face, when embarking on this scholarship development programme in an open distance learning context. Instead of just coordinating the programme, I also became the research supervisor. The local supervisors (who had master's degrees themselves) were not nurses, which meant that I also needed to act as a research supervisor for nursing students. The challenges were multi-dimensional: my mother tongue is Afrikaans, although I am fluent in English; the students were French speaking and their mother tongue was Swahili, with no English understanding - in short, there was no common language we could share. The interpreter was an English teacher, someone who had no background in health-related studies or concepts. The translation of scientific language was therefore problematic and, in the end, translations were not as accurate as they should have been. For 
example, the World Health Organization (WHO) was once translated as the word "who". To guide and facilitate students to be independent researchers, through dialogue and by modeling appropriate research behaviour ${ }^{[10]}$, was extremely difficult in view of the language barriers and cultural differences we were all faced with.

The practicalities pertaining to the research supervision of the students were equally formidable. The geographical distance between me in South Africa and the students in DRC, in effect forced a distance learning approach upon all of us. The inadequate and restricted accessibility of the available resources in the DRC were challenges that restricted communication. The students involved had no previous experience of learning and being supervised through ODL. They did not always have access to the electronic media for example when bills were not paid, the students had no internet access and when the librarian went on a conference, students were left without access to the library. They had no experience in writing research proposals, conducting research or receiving supervision and feedback via electronic media with the assistance of an interpreter. All this was in addition to the fact that they were being supervised by a woman from a different culture who had no understanding of any of the languages the students were literate in.

Interwoven thus are the challenges faced, most of all, the language barrier that had an impact on my experience in all aspects of my supervisory practice, but it can and was overcome by my innovative thinking and problem solving techniques.

\section{Reflective practice}

“Thinking on your feet” or the notion of reflection in action, as described by Donald Schön ${ }^{[11]}$, involves delving deeply into people's experiences and connecting to their feelings. I did this by reflecting on the new situation and on my prior understanding of research supervision. I engaged in the situation, created a "new experiment", and built responses to fit my new situation ${ }^{[12]}$. I had to be open to a variety of research approaches, to a diverse understanding of research methodology and related concepts, and to a culture and language that were totally unfamiliar to me.

Reflective practice refers to a willingness to constantly evaluate and review current practice, to think about what you are doing while you are doing it, and to apply your previous experiences to new situations. It is the key to self-regulatory learning ${ }^{[3]}$ and contributed to my own scholarship development and that of my students.

\section{Design}

I will present this article as a qualitative narrative with a view to providing the reader with a better understanding of my experiences and actions ${ }^{[1]}$. My story is described through narrative reflection, thereby giving the reader the opportunity to read and understand the challenges I faced and the decisions I made; also, and as the reader will see, I shall be describing the consequences of my actions (again, within the same methodological framework). A narrative story provides understanding, can be reflected upon, and can be reanalyzed and understood ${ }^{[13]}$ and you, the reader, will be doing just that (I hope).

\section{Framework}

I used aspects from the guided narrative report, described by Forneris and Pedan-McAlpine ${ }^{[13]}$ and by Ness, Duffy, McCullum and Price ${ }^{[14]}$, as a framework to guide me through this narrative reflective process. I wrote my field notes and reflective report using this same framework (see below):

1) Describe the situation

2) Critical reflection

- What did I think/feel?

- What contributed to my feeling?

Published by Sciedu Press 
- What had an influence on my feeling/thinking?

- Are my feelings clouding the issue?

3) What other perspectives can I consider?

- What did I take for granted?

- Are my assumptions correct?

4) How will I integrate this learning experience with future practice?

- What impact does this experience have on my practice?

5) Debriefing

\section{Data collection}

Although I used a structured guide and framework to collect data, and write my field notes and my report, I shall present the data in an integrated way. I have summarised situations, and my critical reflections on them, in an attempt to convey my message and ensure that the influence that language had on all aspects of the research are clear. I shall describe how I was unprepared and in trouble, and how, initially at least, I felt like an alien; I shall also be describing my critical reflections on all this. Finally, I shall be describing how I tackled situations, how I will integrate my experience in future practice, and my debriefing with a view to ensuring the validity and reliability of my reflections.

\section{Unprepared and in trouble}

My "experiences” started from the moment the plane touched the ground at Lubumbashi airport. My tummy felt tight with tension when I saw the airport. It was small and, outside the airport building, suitcases were packed in rows on the runway with airport personnel inspecting the suitcases while passengers identified which suitcases were theirs. This alarmed me and told me that I was in a very different environment in which people did things very differently. At the time, all I knew was that a person from the university would be fetching me and taking me to where I was supposed to go.

I felt terribly uncomfortable when I stepped out the plane and - to be frank - could see no other white women. People were smiling as I walked towards the airport building and I assumed they were greeting me, but I could not understand what they were saying. However, they looked friendly and I did not feel threatened.

The next moment, a black man approached me. He had a friendly face, smiled, and greeted me in English; he asked whether I was Dr Lizeth from Bloemfontein. What a relief! I had not been forgotten and my "host" could understand English. The Director of the university was also there and introduced me to $\mathrm{Mr} \mathrm{Y}$, who would be my interpreter, and $\mathrm{Mr} \mathrm{Z \text {, }}$ my driver. Later on, I ended up calling these men my guardian angels because, without them, I would have been completely stranded.

I was treated with dignity. For the first time in my life as an academic, I really felt respected, appreciated and cared for. $\mathrm{Mr}$ $\mathrm{Y}$ and $\mathrm{Z}$ took my passport, invitation letter and luggage bag, and left me sitting on a bench. I felt nervous because all my travel documents were taken from me and at the time I did not know why. I found out later on that this was to ensure that the formalities would be taken care of when they came to fetch me. The professor talked to me in broken English on the drive to the hotel, explaining that they wanted to take me to have lunch with other high profile colleagues that I had to meet. Upon arrival at the hotel all the colleagues greeted me with kisses on both cheeks and I was asked to sit on the left-hand side of the rector.

I experienced being "from a foreign country" the moment I got the French menu: the waiter did not understand my order at all. Instead, he simply stared at me and shrugged his shoulders. With relief, I turned to my interpreter. 'I want a leg of lamb’, I said, pointing to my leg. He (my interpreter) started frowning, 'Oh, explain please?' He ordered the food on my behalf. Excited I waited for my order to see what the hotel offered. My plate of food arrived. I stared shocked at the full plate of liver and rice in front of me. The interpreter enthusiastically asked, 'Are you satisfied with your dish?' What could 
I say that would not offend anyone? I do not eat liver but perhaps, by moving my food from one side of the plate to the other, nobody would notice that I was not eating. I felt embarrassed - all the important people were sitting at two separate tables - everyone at my table ordered food while, at the other table, they only ordered drinks (no food). Was this due to a lack of money or a cultural issue?

I needed to phone home and tell them I was safe, so via the interpreter and via the driver I got a local SIM card, but I could not phone because all the instructions were in French.

\section{Critical reflection}

I was in trouble! What about the rest of the 24 hours of the day without the interpreter? How would I order food? How would I communicate? Even worse, he was my only voice to the students! I needed him to translate my conversations with students and supervisors. I needed him. I did not know how we were going to manage the subject. How would he translate methodology related language if he had trouble with translating "leg of lamb"? How could I avoid offending colleagues or students?

I had to admit that I was unprepared; I simply had not expected language to be such a major issue. I believed that the interpreter would always be available to help me and that, in the hotels, the waiters would be able to understand at least basic English. I did not, for once, assume that there would be no colleague or other persons who would be able to communicate with me on a personal or professional level. This was going to be a lonely road.

True to my personality, I comforted myself with the motto: 'Never start something that you will not complete.' There had to be a solution for every challenge I faced, especially in this scholarship development programme. I wanted this programme to be a success: I therefore had to find a way of communicating if I was going to order food, get my cell phone working, and engage with my students. That evening, in the lounge, I managed to focus on the French names of many dishes and ordered some cheese: 'Peux j'avoir un morceau de fromage.'

\section{An alien in the classroom}

The first morning, my driver picked me up at 08:00. I carefully looked at all the advertisement boards and made notes on the drive to the university. I memorised and wrote down the words for water, bread and government, everything that was illustrated on a board and was accompanied by words. I had a few words on my list when we arrived at the university, but writing was very difficult owing to the deep potholes we had to drive over on our way to the university.

I felt embarrassed when I saw the university. I always taught students to never make any assumptions when embarking on research, but that was exactly what I had done. I knew that I would work in a poorly resourced environment, but I was not prepared for the sheer poverty of this environment. There was no running water in the bathrooms to wash my face or hands, no water to drink or to flush the toilet, no lecture room where the students and I could sit around a table. In the lecture room, there was no glass in any of the windows, the roof was broken and I could see the birds flying overhead. The only available new research literature was the literature that I had brought with me, and this was all in English.

However, in front of this dilapidated lecture room, I was met by 15 enthusiastic and willing students. Everyone greeted me in a friendly manner. I had the feeling that they were extremely grateful that I was there, but I felt overwhelmed and stressed, because I could not understand a word of what they were saying. I was the only white female on the entire campus and nobody understood me. I felt like an alien trying to achieve something and I had no idea how I was going to manage.

A student officially welcomed me in French and, with the assistance of the interpreter, I understood and replied. I wanted to use the only available resource in the lecture room, the blackboard, to jot down the essence of the topics and research problems identified by the students. I soon found out that the blackboard was impossible to use because the black had 
faded and the chalk was no longer visible. I realised I had made another assumption when it became clear that none of the students had formulated a problem.

I assumed that the students would be adequately prepared for my visit due to the fact that they had all passed a research module offered by another university. Two months prior to my planned visit, I had prepared research documents for the students to work on. The following documents were translated into French and sent electronically to the interpreter and the professor responsible for the programme for dissemination to the students:

- a research methodology study guide

- a layout of a complete research proposal

- assessment criteria for a mini-dissertation

- a reference guide illustrating the Harvard style of referencing

I asked that all students have a topic, a problem statement and a purpose or aim formulated. I had also made it clear that I expected them to have read about their topic of interest and that they must be ready to present this topic in the classroom on the first day of my visit so that we could start by planning ahead. I asked the students to present what they had prepared in order to have a group discussion.

One by one, the students started to explain the topic and the problem they had identified. I tried to use the topic scoring sheet from Hofstee ${ }^{[15]}$ to help them verify whether they had chosen a good topic or not, but was unable to do so. The students were unable to complete or discuss the topic according to the scoring sheet. In fact, it took hours of translation and interpretation to come to the conclusion that the way I normally go about engaging students with research topics was simply not going to work.

\section{Critical reflection}

Despite having completed a research methodology module, the students had little understanding of research methodology. They were unable to apply the knowledge they had gained to the tasks of identifying a topic, writing a problem statement, and formulating a purpose.

The language problem seemed overwhelming and I felt totally inadequate. Not one student had read any literature on the "topic" of interest. The fact that previous research on a topic has to be known and read about ${ }^{[16]}$ was not important to these students. This might have been because they were all complete novices in research. But another reason might have been that literature study and research were simply not part of their environment. Other contributing factors were the lack of research methodology books and literature, the lack of accessible research articles in French, the lack of mentors in research, and the lack of fiscal resources. I had to come up with alternative methods of supervision rather than rely on my western knowledge of supervision and research methodology. Where research methodology books and modules would normally have served as references, I had to find innovative ways to explain difficult research terminology using objects and concepts that were familiar to these students.

The interpreter did a tremendous job in interpreting all the communication, but when the students answered my questions, I sensed that he, I, and the students had different understandings of the same concept. For a start, the word "questionnaire" meant different things to all of us. In research, I use a questionnaire as a data-collection or measuring instrument. The interpreter translated the term, but the students understood it as a question paper. This might have been due to the fact that the interpreter was an English lecturer and the students were only familiar with examination papers. Nor could the students understand why they needed to do a literature review before they compiled a questionnaire. They said, 'But I know what I want to ask.' 


\section{Active structured strategy}

For me, it was important to create new knowledge through critical reflection; by 'new knowledge', I mean 'knowing how' rather than 'knowing what' ${ }^{[3]}$. I needed to create an innovative method that would enable me to mentor the students so that they could write a research proposal, taking into consideration the lack of physical and human resources, the language barrier, and poor access to electronic media. Also, according to the students, in their environment and community of scholars, there was no tradition of scholarly dialogue and engagement. To counteract misunderstanding and misinterprettation, I had to find objects and concepts known to them rather than textbook explanations (i.e. to explain a research concept). For example, validity and reliability were discussed using the example of the local bottled water: I explained that the bottled water needed to be assessed using the criterion of safe for human consumption, and referring to evidence from the literature. In the same way, the research tool had to be developed using the same validated criteria. Similarly, categories and themes in qualitative data analyses were explained using the classification of items in a pencil case (for writing: pens and pencils, for erasing: TippEx and eraser, for highlighting: highlighter, and for underlining: ruler).

I developed a structured guide to help the students with the format and content of the research proposal. I got the students actively involved by using a step-by-step approach to guide them through a research question (they were used to direct questions). I had to help them to formulate the right questions so that, at the end of the process, they would be able to refine the research problem ${ }^{[2]}$. This prevented them from expecting to be given a research question, which is what many students without any research experience tend to expect ${ }^{[17]}$. I divided the students into three groups after the discussion on part A of the structured guide (see Table 1) working with the same methodology. This active and structured learning strategy ${ }^{[18]}$ made it possible for me to supervise three groups of students while they were all actively involved in similar projects. I assumed it would also contribute to better interpretation on the part of the interpreter, because this approach reduced the number of difficult concepts used. I spent more time with the group than with each individual student. Students also heard explanations of concepts more than once and this, too, contributed to their understanding of the concepts used in research methodology.

The students were guided by questions that they needed to answer as indicated in table 1, supported by evidence from the literature and other sources. We moved on to the next part only after we had answered all questions in a previous part, and thus, at the end of ten days of active involvement, we were able to add all the parts together into one research proposal.

Table 1. Step by Step Structured Guide for Proposal Writing

\begin{tabular}{|c|c|c|c|}
\hline Name of student & Student number & Topic/title & $\begin{array}{l}\text { Email Address: Supervisor's name and } \\
\text { contact details: }\end{array}$ \\
\hline \multicolumn{4}{|c|}{ A photo of the student } \\
\hline \multicolumn{4}{|c|}{$\begin{array}{l}\text { PART A } \\
\text { Identify the topic and problem }\end{array}$} \\
\hline \multicolumn{4}{|c|}{ Complete the following: } \\
\hline \multicolumn{4}{|c|}{ 1. Identify a question/problem in your working environment that you want to answer. } \\
\hline \multicolumn{4}{|c|}{ Why do you want to answer this question? } \\
\hline \multicolumn{4}{|c|}{ Why do you want to do research to get an answer? } \\
\hline \multicolumn{4}{|c|}{ 2. Complete the following sentence: } \\
\hline \multicolumn{4}{|c|}{ The purpose of this research will be to } \\
\hline \multicolumn{4}{|c|}{ Date of discussion } \\
\hline \multicolumn{4}{|l|}{ Field notes: } \\
\hline Refection: & & & \\
\hline
\end{tabular}

(Table 1 continued on page 146) 
Table 1. (Continued)

\section{PART B}

Read six sources (articles, books, policy documents, hospital registers) pertaining to your question and answer the following questions by referring to information or statistics obtained from these sources. You must provide me with evidence that these answers are based on the sources you used.

3.1 What is this problem about?

3.2 Why is it a problem?

3.3 Where specific is this problem?

3.4 What is the extent of this problem?

3.5 Who said this is a problem?

Date for discussion:

Field notes:

Reflection:

PART C

\section{The aim and objectives}

Complete the following sentences:

The aim of this study is to

Look very carefully at what you have written in the above sentence and complete the objectives of your study:

The objectives of this study are to:

identify/describe (what?). (where?) (how?)

identify/describe (what?).

. (where?) (how?)

make recommendations to (do what?). (where?) (how?)

Date for discussion:

Field notes:

Reflection:

\section{PART D}

\section{Population, sampling and ethics}

From what or whom will you obtain the information you need in order to do this research?

Will you need one of the following to collect your data?

Patients (under 18 or above 18 years of age)

Patient records/files (of patients under or above 18 years of age)

Colleagues

Nurses

Documents (e.g. policy documents or examination scripts)

Students (under or above 18 years of age)

Any other, name them

Identify the applicable sources.

Answer the following questions next to each source:

How many of them are there? Give numbers and statistics from a reliable source (e.g. literature or registers).

Will you have easy access to all of them? How?

Will you understand the language of either the person or the documents?

Are there any reasons why some of them may refuse to give you this information?

Do you think that anybody may be harmed by being part of your research?

What will you do to make sure that the information that you obtain will be kept confidential?

Will you be able to get the information from your selected sources?

After you have answered these questions, read about population and sampling in the textbooks and the journal articles.

\section{Date for discussion:}

Field notes:

Reflection: 
Table 1. (Continued)

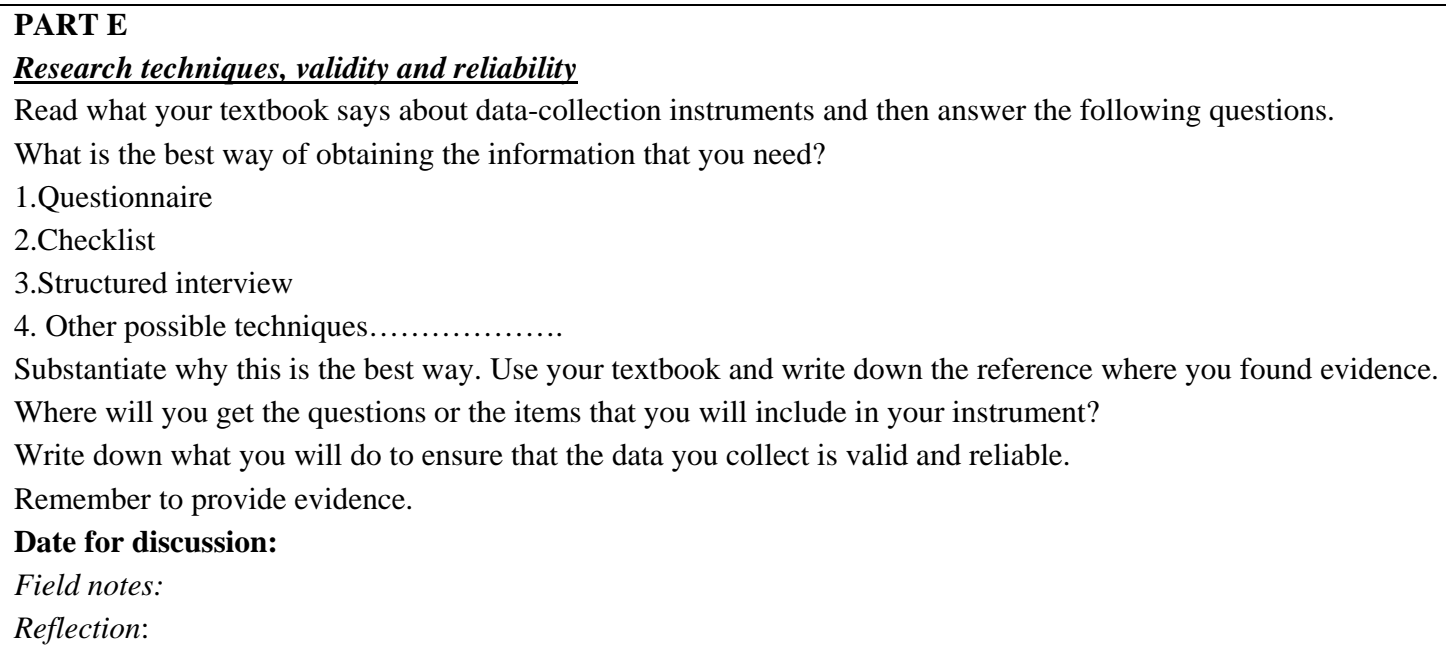

For each student, the topic of the research projects was only formulated after parts A and B were completed in the structured guide. Students were faced with real problems as far as resources were concerned. Working in groups helped them to share resources and provided them with more opportunities for learning that were then mediated by their peer groups ${ }^{[19]}$. Literature searches were combined efforts from both me and the students to ensure progress and to ensure that, at the end of it all, we would have quality research projects.

As Dimitrov's study revealed ${ }^{[17]}$, the students never challenged any of my ideas because they felt I knew better. They never asked many questions because this would make me feel that my explanations were inadequate. The interpreter, being a senior lecturer and colleague from their culture, helped me to understand this. I needed to give them 'permission' to engage in critical thinking and academic argumentation, both of which are acceptable and valued in the western milieu of higher education ${ }^{[18]}$. I also guided the process by structured questions and answers, which allowed them to reflect on their experiences and to ask questions that would stimulate dialogue.

\section{Debriefing}

I used personal critical self-reflection as a form of debriefing as well as post-mortem debriefing sessions with a colleague who was not directly involved in this programme. This enabled me to give a pure reflection of my account ${ }^{[19]}$.

\section{Integrate my experience in future practice}

To reiterate: the language barrier was the most challenging aspect of this supervision experience. Many studies on internationalisation and research supervision emphasise the importance of English language proficiency ${ }^{[20]}$, but this was a luxury that the students and I simply did not have. It was not only grammar that was a problem, but also the tone - this, too, got lost in translation, either by the interpreter or by internet messages (which had to be translated). This is something that I will always remember whenever, in future, I have to give feedback to students in the ODL environment. I would recommend that supervisors never underestimate their own approach to life and their ability to solve 'unsolvable' problems. Once you allow the student into a programme, the institution, which invariably means the supervisor, has the responsibility of ensuring that the student has the support he or she needs to complete the master's degree programme. The fact that students do not respond to feedback or correspondence via e-mail might well be owing to internet access problems rather than owing to a lack of commitment. The tone of the feedback is therefore important: the student needs to remain motivated. 
Explaining and giving electronic feedback pertaining to research methodology and difficult concepts via the internet and an interpreter was challenging, but a solution was found. This solution involved using a question-and-answer approach, group supervision and using examples of local concepts, objects and structures known to the students. The reflection on my experience redefined my supervisory practice into a practice that includes mentoring skills as I discovered innovative ways to use cultural diversity, language barriers and indigenous knowledge to build bridges 'over' the 'river' of western research methodology. Students became actively involved and came to understand the process and the concepts. Having to use evidence from the literature to justify their answers familiarised the students with the important skills of literature searches and analysis. Feedback on every question (i.e. the interactive approach) was enforced and this, too, contributed to the success and progress of these students.

Perhaps I should end this article by saying that I will always remember the date of 3 August 2012, when 10 out of the 15 students received their degrees, the first master's degrees in nursing to be conferred on any student in the DRC. Their supervisory journey as novices may now require further support before they can belong and feel part of the global community of scholars.

'I did not understand their language, they did not understand mine, together we wanted to succeed, and we have.'

\section{Acknowledgements}

NEPAD for supporting this scholarship development initiative and the University of the Free State for the time to achieve my goal.

\section{Reference}

[1] Mahoney, D., and McCahill, L., and McIntosh, B., and Reed, B., 2007, 'Quality of life: An Approach integrating opportunities, human needs, and subjective well-being', Ecological Economics. 2007; 61(2-3): 267-276.

[2] Burns N, Grove SK. The Practice of nursing research: Conduct, critique and utilization. 6th edition. St Louis, Missouri: Elsevier Saunders, 2009.

[3] Morgan, J., and Rawlinson, M., and Weaver, M. 'Facilitating online reflective learning for health and social care professionals', Open Learning. 2006; 21(2): 167-176. http://dx.doi.org/10.1080/02680510600715594

[4] Grant, B, Manathunga, C. Supervision and cultural differences: rethinking institutional pedagogies. Innovations in Education and Teaching International. 2011; 48(4): 153-354. http://dx.doi.org/10.1080/14703297.2011.617084

[5] Marmolejo, F. 'Internationalization of Higher Education: The Good, the Bad, and the Unexpected'. The Chronicle of Higher Education. 2010. Available from:

http://chronicle.com/blogs/worldwise/internationalization-of-higherr-education-the-good-the-bad-and-the-unexpected/27512

[6] HEALTHGAP, 2007, 'Healthcare Worker Shortage Crisis in Africa: Fact Sheet'. Available from: http://www.healthgap.org/hcw/documents/HealthcareWorkerShortageFact_Sheet_UCGH.pdf. 27 January 2012.

[7] Congo Democratic Republic. [Sa]. Researching Virtual Initiatives in Education. Available from: www.virtualcampuses.eu/index.php/Congo_Democratic_Republic (27 January 2012).

[8] Memorandum of Understanding between University of KwaZulu-Natal and University of the Free State, Faculty of Health Sciences', Building Nursing and Midwifery Capacity in East Africa. Bloemfontein, Free State, 6 December 2006.

[9] Wikipedia, 2012, 'Demographics of the Democratic Republic of the Congo'. Available from: http://en.wikipedia.org/wiki/Demographics_of_the_Democratic_Republic_of_the_Congo,27 January 2012.

[10] Manathunga, C. 'Supervision as mentoring: The role of power and boundary crossing', Studies in Continuing Education. 2007; 29(2): 207-221. http://dx.doi.org/10.1080/01580370701424650

[11] Schön, D. The reflective practitioner: how professionals think in action. Boston: Arena Publishing. 1983.

[12] Smith, M.K. 'Donald Schön: Learning, reflection and change, the encyclopaedia of informal education'. Available from: http://www.infed.org/thinkers/et-schon.htm. 22 May 2012.

[13] Forneris, CG, Pedan-McAlpine, CJ. Contextual Learning: A Reflective Learning Intervention for Nursing Education'. International Journal of Nursing Education and Scholarship. 2006; 3(1): 1-16. PMid:16646944 http://dx.doi.org/10.2202/1548-923X.1254 
[14] Ness, V., Duffy, K., McCallum, J., Price, L. 'Supporting and mentoring nursing students in practice', Nursing Standard. 2010; 25(1): 41-46. PMid:20949750

[15] Hofstee, E., 2006, Constructing a Good Dissertation, Sandton, Gauteng: EPE.

[16] De Vos, AS, Strydom, H, Delport, CB, Fouche, CSL. Research at Grass Roots. Pretoria: Van Schaik Publishers, 2011,

[17] Cryer, P. Language and Cultural issues. Available from: www://postgraderesources.info/supervisor-resources08-language.htm (19 March 2012).

[18] Onwuegbuzie, A.J., Leech, N.L., and Collins, K.M.T. 'Interviewing the Interpretive Researcher: A Method for Addressing the Crisis of Representation, Legitimation and Praxis', International Journal of Qualitative Methods. 2008; 7(4): 1-16.

[19] Samara, A. 'Group Supervision in graduate education: a process of supervision skill development and text improvement', Higher Education Research \& Development. 2006; 25(2): 115-129. http://dx.doi.org/10.1080/07294360600610362

[20] Guerin, C, Green, I. 'Research Supervision and Internationalisation: belonging to the global academy', Challenging Higher Education: Knowledge, policy and practice, Society for Higher Education. New Port. 2009. 